\title{
Angiotensin Inhibitors as Treatment of Sunitinib/Pazopanib-induced Hypertension in Metastatic Renal Cell Carcinoma
}

\section{Penttila, Patrick}

2017-06

Penttila , P , Rautiola , J , Poussa , T , Peltola , K \& Bono , P 2017 , ' Angiotensin Inhibitors as Treatment of Sunitinib/Pazopanib-induced Hypertension in Metastatic Renal Cell

Carcinoma ' , Clinical Genitourinary Cancer , vol. 15 , no. 3 , pp. 384-390 . https://doi.org/10.1016/j.clgc.2016.12.016

http://hdl.handle.net/10138/297831

https://doi.org/10.1016/j.clgc.2016.12.016

publishedVersion

Downloaded from Helda, University of Helsinki institutional repository.

This is an electronic reprint of the original article.

This reprint may differ from the original in pagination and typographic detail.

Please cite the original version. 


\title{
Angiotensin Inhibitors as Treatment of Sunitinib/Pazopanib-induced Hypertension in Metastatic Renal Cell Carcinoma
}

\author{
Patrick Penttilä, ${ }^{1}$ Juhana Rautiola, ${ }^{1}$ Tuija Poussa, ${ }^{2}$ Katriina Peltola, ${ }^{1}$ Petri Bono ${ }^{1}$
}

\begin{abstract}
Previous preclinical research suggests that angiotensin system inhibitors may have a direct anti-angiogenic effect that may be synergistic with the currently available angiogenesis inhibitors. In this retrospective study, we reviewed 303 patients with metastatic renal cell carcinoma treated with first-line angiogenesis inhibitors. Our results demonstrate a longer overall and progression-free survival for angiotensin system inhibitor users among patients with treatment-related hypertension. If validated, these results may guide the choice of antihypertensive medication among patients being treated with angiogenesis inhibitors.

Background: Research suggests that baseline use of angiotensin system inhibitors (ASIs) improves outcome in patients with metastatic renal cell carcinoma (mRCC), but it remains unknown whether the type of antihypertensive medication used to initiate management at onset of treatment-induced hypertension (HTN) is associated with outcome. We evaluated the association of ASIs and outcome among patients with mRCC treated with first-line tyrosine kinase inhibitors (TKIs). Patients and Methods: We identified 303 consecutive patients with mRCC who were treated with sunitinib or pazopanib in a single university hospital cancer center. Statistical analyses were performed using the Kaplan-Meier method and Cox regression adjusted for known risk factors. Results: Progression-free survival (PFS) and overall survival (OS) were similar among patients with baseline HTN $(n=197 ; 65 \%)$ versus patients with no baseline HTN ( $n=106 ; 35 \%)$ (PFS; $P=.72$ ) (OS; $P=.54)$. There was a significant difference between patients with treatment-induced HTN $(n=110)$ versus patients with no treatment-induced HTN $(n=193)$ for PFS $(15.6$ vs. 6.4 months, respectively; $P<.001)$ and OS (34.9 vs. 13.9 months, respectively; $P<.001)$. Use of ASIs at baseline $(n=126 ; 41.6 \%)$ had no impact on outcome as compared with patients receiving other antihypertensive medication $(n=71 ; 23.4 \%)$ or with patients with no baseline antihypertensive medication $(n=106 ; 35.0 \%)$. Among patients with TKI-induced HTN $(n=110)$, however, ASI users $(n=91)$ demonstrated improved OS (37.5 vs. 18.1 months; $P=.001)$ and PFS (17.1 vs. 7.2 months; $P=.004)$ versus ASI nonusers $(n=19)$, respectively. Conclusion: Our results demonstrate survival benefit for ASI users among patients with TKI-induced HTN. These results, however, require further validation in a prospective setting.
\end{abstract}

Clinical Genitourinary Cancer, Vol. 15, No. 3, 384-390 @ 2016 Elsevier Inc. All rights reserved. Keywords: Angiogenesis, Angiotensin system inhibitors, Hypertension, Renal cancer, Tyrosine kinase inhibitors

\section{Introduction}

Hypertension (HTN) is a well-known side effect associated with anti-vascular endothelial growth factor (VEGF) therapies in

${ }^{1}$ Comprehensive Cancer Center, Helsinki University Central Hospital, Helsinki, Finland

${ }^{2}$ STAT-Consulting, Nokia, Finland

Submitted: Jun 16, 2016; Revised: Dec 6, 2016; Accepted: Dec 10, 2016; Epub: Dec 22, 2016

Address for correspondence: Patrick Penttilä, MD, Comprehensive Cancer Center, Helsinki University Central Hospital, P.O. Box 180, FIN-00029 HUS, Helsinki, Finland

E-mail contact: patrick.penttila@helsinki.fi metastatic renal cell carcinoma (mRCC), and numerous studies have reported it as predictive of better outcome for patients treated with tyrosine kinase inhibitors (TKIs).

The pathogenesis of treatment-related HTN is likely multifactorial. Evidence suggests that inhibition of VEGF leads to impairment of vasodilatory mechanisms, thus increasing the resistance of peripheral blood vessels. ${ }^{6,7}$ Structural or functional vascular rarefaction caused by antiangiogenic agents, ${ }^{8}$ as well as decreased glomerular filtration rate and increased sodium and water retention by the kidney, owing to placenta-derived soluble antiangiogenic factors, ${ }^{9}$ may also play a role in the development of therapy-related HTN. 
HTN may also contribute to the development of RCC based on its significantly higher incidence among patients with mRCC. ${ }^{4,10,11}$ A recent study consisting of patients treated with sunitinib, a standard first-line treatment, suggested that baseline HTN might be associated with better outcome. ${ }^{12}$

Angiotensin system inhibitors (ASIs), which are commonly used as antihypertensive agents, have been of great interest in treatment of mRCC-related HTN. Xenograft studies have demonstrated that angiotensin II receptor-deficient mice have reduced angiogenesis and tumor growth rates compared with wild-type mice, ${ }^{13}$ and preclinical studies have shown that ASIs possess antiangiogenic potential. $^{14-16}$

In 2010 Dolley-Hitze et $\mathrm{al}^{17}$ demonstrated that overexpression of angiotensin II receptors (AT1-R and AT2-R) in mRCC correlates with more aggressive tumor behavior and shorter progression-free survival (PFS). Keizman et $\mathrm{al}^{18}$ were the first to illustrate that baseline use of ASIs may improve PFS in sunitinib-treated patients with mRCC. More recently, in a large pooled retrospective analysis, McKay et $\mathrm{al}^{19}$ confirmed that ASI users may have an improved survival over ASI nonusers. However, it remains unclear whether choosing ASIs as treatment at onset of therapy-related HTN has beneficial effect on outcome among patients with mRCC.

The aim of this study was to examine the potential impact of the use of ASIs on outcome among a large cohort of patients with mRCC treated with first-line TKIs, and to investigate whether the selection of ASIs as anti-HTN agents improve outcome of patients with mRCC as compared with patients treated with other antiHTN agents (such as $\beta$-blockers/Ca-blockers/diuretics).

\section{Patients and Methods Patients and Treatment}

A total of 303 consecutive patients with mRCC were treated with a first-line anti-VEGF agent, of which 267 patients were treated with sunitinib and 36 with pazopanib at the Cancer Center, Helsinki University Central Hospital, between October 18, 2006 and December 31, 2014. The data collected from the hospital case records included patient demographic features, treatments given, adverse events (AEs), hospitalizations, and outcome data.

None of the patients had received prior TKI therapy. Twentytwo $(7.3 \%)$ patients had received prior interferon alfa. Both sunitinib and pazopanib were administered according to standard care until disease progression or unacceptable toxicity. Twenty-three percent $(\mathrm{n}=59)$ of the patients started sunitinib with intermittent dosing (4 weeks on-treatment, 2 weeks off-treatment) and 77\% ( $\mathrm{n}=208$ ) with continuous dosing. Pazopanib was administered continuously.

\section{Assessment of Tumor Response and AEs}

Response to treatment was assessed by physical examination and computed tomography at 8 to 12 week intervals. Treatment efficacy was reported according to Response Evaluation Criteria in Solid Tumours v. 1.0 (RECIST). ${ }^{20}$ AEs were captured every 4 to 6 weeks and were graded according to Common Terminology Criteria for Adverse Events (CTCAE) version 3.0. ${ }^{21}$ HTN was graded as follows: Grade 1, transient ( $<24$ hours), asymptomatic, blood pressure (BP) rise by $20 \mathrm{mmHg}$ (diastolic) or to $>150 \mathrm{mmHg}$, if previously normal; Grade 2, recurrent, persistent, or symptomatic rise in diastolic $\mathrm{BP}>20 \mathrm{mmHg}$ or systolic $\mathrm{BP}$ rise to $>150$ / $100 \mathrm{mmHg}$, if previously normal (monotherapy with antihypertensive agents may be indicated); Grade 3, requiring more than 1 drug or more intensive therapy than previously.

\section{Assessment of BP and Use of Antihypertensive Agents}

$\mathrm{BP}$ was assessed at baseline and at the end of each treatment cycle. The patients were additionally instructed to measure their BP on a daily basis and to contact their physician for systolic BP > $150 \mathrm{mmHg}$ or diastolic BP $>90 \mathrm{mmHg}$. Baseline HTN was defined based on International Classification of Diseases, Tenth Revision (ICD-10) diagnosis code for HTN in the patient case records or as the use of 1 or more antihypertensive agents prior to treatment initiation. Treatment-induced HTN was defined as recurrent, persistent, or symptomatic rise in diastolic BP of $>$ $20 \mathrm{mmHg}$ or systolic BP rise to $>150 \mathrm{mmHg}$, if previously within normal range (CTCAE, grade $\geq 2$ ). These data were captured from patient case records. The use of antihypertensive medication was obtained from the patient case records before treatment initiation and during follow-up. ASIs included angiotensin-convertingenzyme inhibitors and angiotensin receptor blockers. The baseline use of ASIs and other antihypertensive agents was defined as patients receiving ASIs or other antihypertensive agents prior to treatment initiation. The initiation of ASIs and other antihypertensive agents, as well as dose escalations, as treatment of TKIinduced HTN was considered to have occurred when it was documented on patient case records.

\section{Statistics}

In this retrospective study, the patients' characteristics were described overall and by HTN and ASI user status at baseline. The groups were compared using the Mann-Whitney $U$ test for continuous data and the $\chi^{2}$ test for categorical data. The 2 endpoints in the study were (1) overall survival (OS), defined as the time from treatment initiation to death, whatever the cause; and (2) PFS, defined as the time from treatment initiation to the first event (tumor progression or death from any cause). The Kaplan-Meyer method was used to estimate the median survival times with 95\% confidence intervals (CIs) for both OS and PFS, censoring the patients who were alive or had no disease progression at the last follow-up visit. The univariate Cox proportional hazards models were used to compare the survival times between groups that were defined according to the HTN and ASI user status. In addition, the multivariate Cox proportional hazard models were performed, and the additional predictors were: number of metastatic sites, prior nephrectomy, Heng risk criteria (Karnofsky performance status less than $80 \%$; diagnosis-to-treatment interval less than 1 year; and abnormal levels of hemoglobin, platelets, neutrophils, or calcium), ${ }^{22}$ and treatment-induced HTN. The results are given as nonadjusted or adjusted hazard ratios (HRs) with 95\% CIs. Subgroup analysis was performed on patients developing treatment-associated HTN.

Because treatment-associated HTN, and therefore the use of ASIs and other antihypertensive medication, is a time-dependent covariate, a landmark survival analysis with the landmark set at 3 months after date of initiation of anti-VEGF therapy was applied to avoid bias from longer treatment. According to the landmark method, patients with short treatment (ie, less than 3 months) were excluded. 


\section{Angiotensin Inhibitors and mRCC}

PFS and OS landmark analyses included those patients who were alive and had no disease progression before the landmark time point. In the landmark analysis, OS and PFS were defined as the time from the landmark to progression or death from any cause.

Statistical tests were 2 -sided, and $P$-values $<.05$ were considered as statistically significant. Analysis was performed using IBM SPSS Statistics for Windows (version 23.0; IBM Corp, Armonk, NY).

\section{Results}

\section{Patient Characteristics}

The study population consisted of 303 patients. Patient characteristics are shown in Supplemental Table 1 (in the online version). The median age was 67 years (range, 22-92 years), and the median follow-up time of patients alive was 53.3 months. Most patients had undergone prior nephrectomy $(79.5 \%)$, and the majority had RCC with a clear-cell histology (87.2\%). Out of the 303 patients, 181 (59.7\%) stopped treatment owing to progression, and 95 (31.4\%) were without progression ( 80 for AEs, 15 for other reasons). The remaining 27 patients $(8.9 \%)$ continued treatment at the time of data cutoff. OS and PFS for the study population were 20.3 months (95\% CI, 17.0-23.6 months) and 8.2 months (95\% CI, 6.9-9.6 months), respectively. Of the evaluable patients, $5(1.8 \%)$ had complete response, 83 (29.7\%) had partial response, 134 (48.0\%) had stable disease, and $57(20.4 \%)$ had progressive disease as their best response.

\section{Effect of HTN and ASIs on Outcome}

A total of 197 (65\%) patients had baseline HTN. Of these, 126 (64\%) patients had ASI (angiotensin-converting-enzyme inhibitor or angiotensin receptor blocker) as baseline antihypertensive medication either as monotherapy or in combination with other approved antihypertensive medication.

Patients with HTN and patients with ASI were significantly older compared with patients without HTN and without ASI. There were no statistically significant differences in other patient characteristics. In univariate analysis, there was no significant difference in outcome for patients with baseline HTN versus no HTN at baseline in OS (20.3 months [95\% CI, 16.4-24.2 months] vs. 20.1 months [95\% CI, 15.5-24.7 months]; respectively) or PFS (8.2 months [95\% CI, 6.6-9.7 months] vs. 8.2 months [95\% CI, 5.4-11.0 months]; $P=.54$ and $P=.72$, respectively). When comparing patients receiving ASIs at baseline $(n=126)$ with patients receiving other antihypertensive medication $(\mathrm{n}=71)$ or with patients with no antihypertensive medication at baseline $(\mathrm{n}=106)$, there was no significant difference in outcome for OS (22.3 months [95\% CI, 18.9-25.7 months] vs. 16.5 months [95\% CI, 10.8-22.2 months] vs. 20.1 months [95\% CI, 15.5-24.7 months]; respectively, with global $P=.35$ ) or PFS (8.6 months [95\% CI, 6.3-10.9 months] vs. 7.3 months [95\% CI, 5.0-9.6 months] vs. 8.2 months [95\% CI, 5.4-11.0 months]; respectively, with global $P=.63$ ).

Patients with treatment-induced HTN $(\mathrm{n}=110)$ had significantly longer OS (34.9 months [95\% CI, 28.2-41.6 months] vs. 13.9 months [95\% CI, 10.4-17.4 months], respectively; unadjusted HR, 0.41; 95\% CI, 0.30-0.55; $P<.001)$ and PFS (15.6 months [95\% CI, 11.6-19.7 months] vs. 6.4 months [95\% CI, 5.6-7.3 months], respectively; unadjusted $\mathrm{HR}, 0.43$; 95\% CI, 0.33-0.56; $P<.001)$ when compared with patients who did not develop HTN

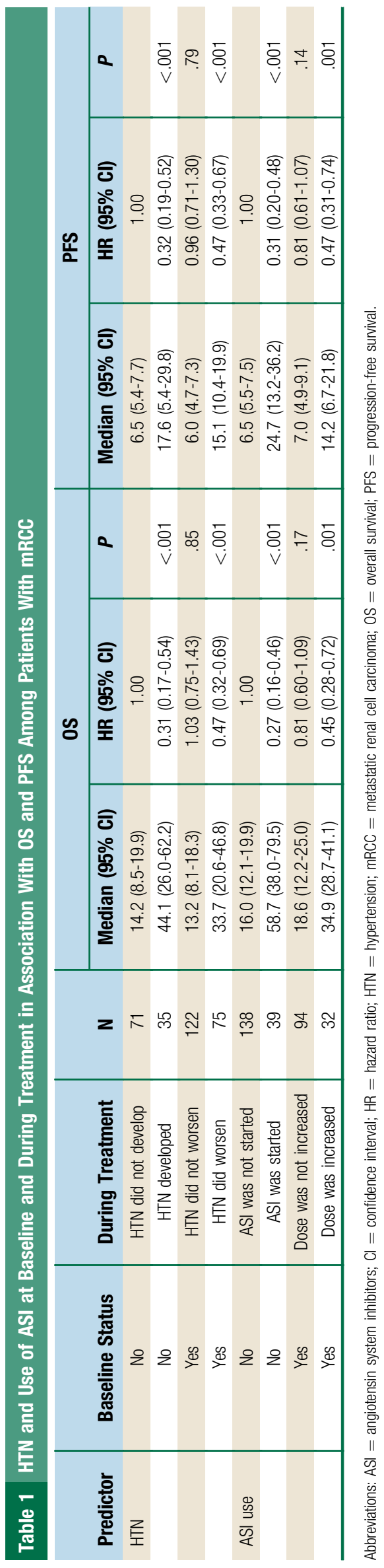


during therapy. For patients receiving ASI either as a new drug $(\mathrm{n}=39)$ or having ASI dose intensified $(\mathrm{n}=32)$ during TKI treatment (total $\mathrm{n}=71$ ), there was a significant difference for both OS (37.7 months [95\% CI, 26.0-49.5 months] vs. 16.5 months [95\% CI, 12.9-20.2 months], respectively; unadjusted HR, 0.38; 95\% CI, 0.26-0.54; $P<.001)$ and PFS (16.7 months [95\% CI, 6.1-27.2 months] vs. 6.6 months [95\% CI, 5.8-7.5 months], respectively; unadjusted $\mathrm{HR}, 0.41 ; 95 \% \mathrm{CI}, 0.30-0.57$; $P<.001$ ), when compared with patients who did not receive ASIs as new antiHTN medication or have their pre-existing ASI dose escalated $(\mathrm{n}=232)$. Factors associated with OS and PFS in univariate analysis are shown in Supplemental Table 2 (in the online version).

To analyze the impact of HTN and ASI use in detail, we divided all patients into 4 groups according to HTN and ASI user status (Table 1). The outcome for both OS and PFS was best among patients who developed HTN during treatment or started ASI as a new anti-HTN medication during treatment.

To further examine the effects of ASI use on outcome, we divided the patients with TKI-induced HTN $(n=110)$ into 4 groups according to baseline ASI use and ASI-initiation/dose-escalation during treatment (Table 2). With ASI nonusers as the reference group, this subgroup analysis suggests that both OS and PFS are longest among patients who started using ASI as a novel treatment for TKI-induced HTN (OS; $P<.001$ ) (PFS; $P=.001$ ). Patients who used ASIs at baseline and either had their ASI dose intensified or received other antihypertensive medication as treatment of TKIinduced HTN also had both longer OS $(P=.01$ and $P=.02$, respectively) and PFS $(P=.048$ and $P=.06$, respectively) when compared with the reference group. Among patients with TKIinduced HTN, ASI users (ASI during baseline and/or during treatment; $\mathrm{n}=91$ ) had significantly longer OS of 37.5 months (95\% CI, 28.2-46.8 months) versus 18.1 months (95\% CI, 14.0-22.2 months; $P=.001)$ and PFS of 17.1 months $(95 \% \mathrm{CI}$, 9.3-24.9 months) versus 7.2 months (95\% CI, 3.7-10.7 months; $P=.004)$ as compared with ASI nonusers $(\mathrm{n}=19)$. These groups were balanced regarding relevant clinicopathologic covariables. Patient characteristics are shown in Supplemental Table 3 (in the online version). A pooled survival analysis of all ASI users versus ASI nonusers among patients with TKI-induced HTN is depicted in Figure $1 \mathrm{~A}$ and $\mathrm{B}$.

\section{Multivariate Survival Analysis}

To investigate the independent impact of different factors on outcome, we performed a multivariate survival analysis adjusted for number of metastatic sites, prior nephrectomy, Heng criteria, and treatment-induced HTN. Because neither HTN nor ASI use at baseline had a statistically significant impact on outcome in the univariate analysis, they were excluded from the multivariate analysis. Owing to the strong positive correlation between treatmentinduced HTN and ASI use during treatment (Cramer's phi $=0.73$ ), only HTN was entered in the analysis. In the multivariate analysis, treatment-induced HTN was statistically associated with both longer OS (adjusted HR, 0.49; 95\% CI, 0.35-0.67; $P<.001$ ) and PFS (adjusted HR, 0.50; 95\% CI, 0.38-0.67; $P<.001)$. We additionally performed a multivariate analysis among patients with TKI-induced HTN. The final model was adjusted for Heng risk criteria and ASI user status. In this analysis,

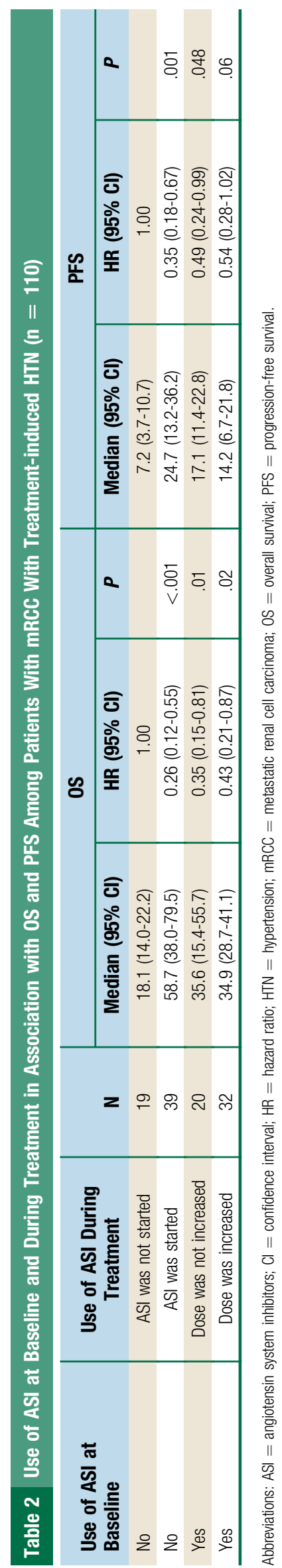


Figure 1 Kaplan-Meier Survival Curves for Overall Survival (A) and Progression-free Survival (B) in Patients With mRCC With TKIinduced Hypertension $(n=110)$. The Cox Proportional Hazard Model Was Used to Compare the ASI Users (ASI During

Baseline and/or During Treatment, $n=91)$ With the ASI Nonusers $(n=19)$

A

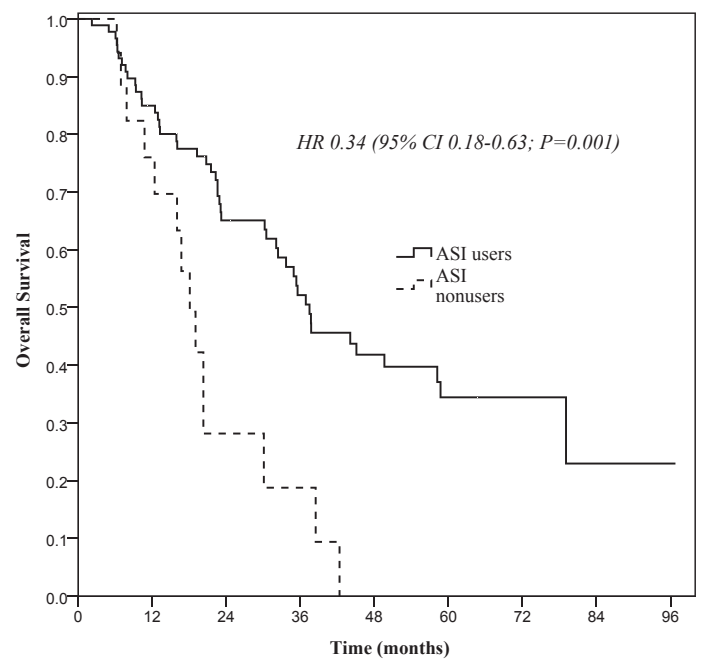

B

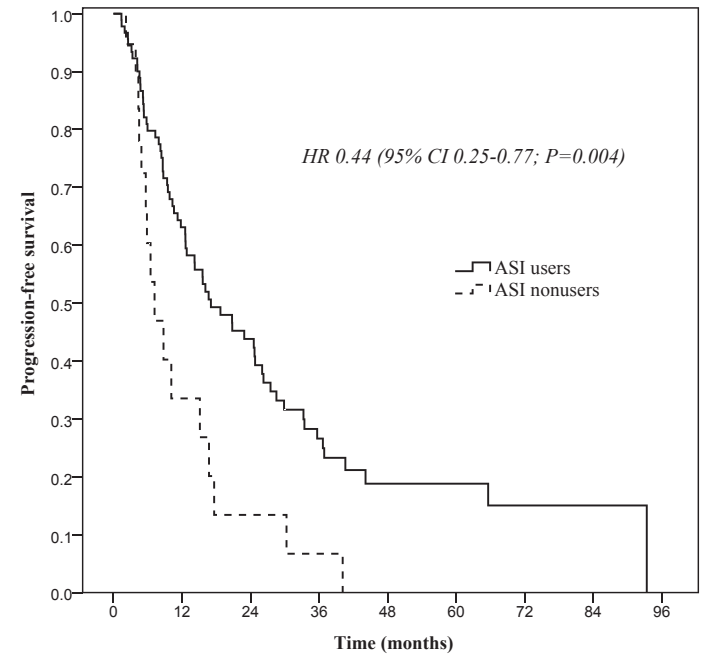

Abbreviations: $\mathrm{ASI}=$ angiotensin system inhibitors; $\mathrm{Cl}=$ confidence interval; $\mathrm{HR}=$ hazard ratio; $\mathrm{mRCC}=$ metastatic renal cell carcinoma; $\mathrm{TKI}=$ tyrosine kinase inhibitors.

the use of ASIs had an independent protector effect for OS (adjusted HR, 0.35; 95\% CI, 0.18-0.66; $P=.001$ ) and PFS (adjusted HR, $0.42 ; 95 \% \mathrm{CI}, 0.23-0.77 ; P=.005)$.

\section{Landmark Analysis}

To verify whether the early incidence of treatment-induced HTN and ASI use was truly predictive, we performed a 3-month landmark analysis. For this purpose, each patient's HTN status, as well as use of ASIs, was determined within the landmark time point. In this analysis, patients with treatment-induced HTN $(\mathrm{n}=81)$ had significantly longer OS (34.5 months [95\% CI, 30.5-38.5 months] vs. 17.1 months [95\% CI, 14.3-19.9 months]; $P<.001$ ) and PFS (13.7 months [95\% CI, 7.5-19.9 months] vs. 4.9 months [95\% CI, 3.8-6.1]; $P<.001)$ than patients with no development of HTN $(n=172)$. Similar to the results of the primary analysis, among patients with TKI-induced HTN, ASI users $(n=68)$ had significantly longer OS (42.1 months [95\% CI, 17.4-66.8 months] vs. 17.3 months [95\% CI, 13.9-20.7 months]; $P=.004)$ and PFS (15.7 months [95\% CI, 7.6-23.8 months] vs. 5.8 months [95\% CI, 0.3-11.2 months]; $P=.011$ ) as compared with ASI nonusers $(\mathrm{n}=13)$.

\section{Discussion}

Our present study suggests that patients treated with anti-VEGF agents may benefit from ASI use as treatment of TKI-induced hypertension. As depicted in Table 2, patients receiving ASI as novel anti-HTN medication for treatment-induced HTN had the longest OS and PFS. Furthermore, we demonstrate that OS and PFS were significantly longer among patients with treatment-related HTN for ASI users versus ASI nonusers (Figure 1A and B). These differences remained significant in a 3-month landmark analysis and in a multivariate model adjusted for Heng risk criteria and ASI user status.

Since Keizman et $\mathrm{al}^{18}$ first demonstrated a significant 7 -month increase of PFS (HR, 0.54; $P=.02$ ) in favor of ASI users in mRCC, a few studies have examined the impact of ASI use on outcome among patients with mRCC. Recently, Izzedine et $\mathrm{al}^{12}$ demonstrated a survival benefit for patients receiving ASI before or within 1 cycle of sunitinib treatment (OS; HR, 0.40; 95\% CI, 0.24-0.66; $P<.001$ and PFS; HR, 0.55; 95\% CI, 0.35-0.86; $P=.009)$. Similar results were reported by McKay et $\mathrm{al}^{19}$ in a large retrospective analysis. To the best of our knowledge, however, there are no reports on whether the selection of ASIs as treatment at onset of TKI-induced HTN affects outcome.

Considering the growing evidence implicating the angiotensin system as a potential factor in the tumorigenesis process, it remains unclear why no statistically significant difference in outcome for baseline ASI users versus ASI nonusers was seen. We hypothesize that the rather small number of patients in our patient cohort might fail to recognize the differences as statistically significant. Additionally, our patient cohort differs somewhat from those used by McKay et el and Keizman et al regarding prior systemic therapy, incidence of treatment-associated HTN, and OS for the whole patient cohort. ${ }^{18,19}$ Lastly, in these studies, ASI use was determined as ASI use at baseline or within 1 month of therapy, which might reflect and correlate to some extent with the onset of TKI-induced hypertension - a well-known predictor of anti-VEGF treatment efficacy.

Our data suggests that patients who benefit from anti-VEGF treatment the most also benefit the most from ASI, given that 


\section{Patrick Penttilä et al}

statistically significant differences were not seen in outcomes between ASI users and ASI nonusers among patients who did not develop TKI-induced HTN in contrast to patients who did develop HTN during treatment. We hypothesize that this might represent a synergistic effect between anti-VEGF agents and ASIs, because there is evidence showing that angiotensin II plays a role in VEGFdependent angiogenesis. ${ }^{23,24}$ Miyajima et $\mathrm{al}^{25}$ reported that candesartan alone dramatically prevents development of metastatic lung nodules along with the inhibition of neovascularization and VEGFexpression in a murine RCC model. More recently, in another murine RCC model, telmisartan was shown to potentiate the antiangiogenic effects of sunitinib. ${ }^{26}$ Preclinical data suggest ASIs to have anti-tumor and antiangiogenic potential in other cancer types as well. ${ }^{27,28}$

Several studies have reported TKI-induced HTN as a predictor of treatment efficacy. ${ }^{2-5,12,19}$ In our analysis, we were able to confirm these findings with TKI-induced HTN having an independent effect on outcome (HR, 0.49; 95\% CI, 0.35-0.67; $P<.001$ and HR, $0.50 ; 95 \%$ CI, $0.38-0.67 ; P<.001)$ for OS and PFS, respectively. There was no correlation between baseline HTN and outcome; a result in line with earlier findings. ${ }^{19}$

Although the present series was retrospective in nature, it was based on consecutive patients. There are some limitations to our study, however. Our study population represents a heterogeneous group of patients including different histologic variants of RCC treated with either sunitinib or pazopanib. No conclusions regarding other anti-VEGF agents can be drawn. Data were lacking regarding the precise dosing, schedule, and possible discontinuations of ASI use, and we assumed on-label usage of these agents. Additionally, data were lacking regarding why some patients were treated with ASIs and some not. This uncertainty related to ASI selection criteria might represent possible confounding factors (eg, renal dysfunction that were not adjusted for in the analysis). In statistical analysis, ASI use could not be verified as an independent predictor of better outcome in a multivariable model for the entire cohort owing to the strong correlation of treatment-induced HTN and ASI use. Furthermore, the total number of 19 ASI nonusers in the subgroup of patients with TKI-induced HTN is relatively small.

\section{Conclusions}

We conclude that the present data demonstrate both a prolonged OS and PFS for ASI users over ASI nonusers among patients with treatment-related HTN in a large cohort of patients with mRCC. In recognition of the limitations of the present series and the fact that ASI use could not be verified as an independent predictor of outcome for the entire cohort due to strong correlation of ASI use and TKI-induced HTN, further studies investigating ASIs in this setting are warranted to confirm our findings. However, should these results be validated in a prospective setting, in the absence of contraindications, selecting ASIs as a first anti-HTN agent might offer a survival benefit as well as feasible management of TKI-induced HTN in patients with mRCC.

\section{Clinical Practice Points}

- HTN is a class effect of anti-VEGF agents used in the treatment of mRCC.
- Preclinical studies suggest that ASIs may have direct antiangiogenic effects, which may be synergistic with the currently available angiogenesis inhibitors.

- Angiotensin inhibitors are widely used in the treatment of HTN. It remains unclear, however, whether choosing ASIs as treatment of therapy-related HTN has beneficial effect on outcome among patients with mRCC.

- We analyzed anti-HTN treatment among 303 consecutive patients with mRCC treated with first-line TKIs.

- In this study, we demonstrate a longer OS (adjusted HR, 0.35; 95\% CI, 0.18-0.66; $P=.001$ ) and PFS (adjusted HR, 0.42; 95\% CI, 0.23-0.77; $P=.005)$ for ASI users among patients with TKI-induced HTN.

- If validated, these results may guide the choice of antihypertensive medication among patients being treated with angiogenesis inhibitors.

\section{Disclosure}

P. Penttilä has received honoraria from Novartis. K. Peltola has received honoraria from Novartis, BMS, Pfizer, Amgen, Astellas, Sanofi, Merck, and Eli Lilly. P. Bono has received research funding from Novartis and honoraria from Pfizer, Novartis, Orion Pharma, BMS, and MSD. All other authors state that they have no conflicts of interest.

\section{Supplemental Data}

Supplemental tables accompanying this article can be found in the online version at http://dx.doi.org/10.1016/j.clgc.2016.12.016.

\section{References}

1. Rixe $\mathrm{O}$, Billemont B, Izzedine H. Hypertension as a predictive factor of sunitinib activity. Ann Oncol 2007; 18:1117.

2. Rini BI, Cohen DP, Lu DR, et al. Hypertension as a biomarker of efficacy in patients with metastatic renal cell carcinoma treated with sunitinib. J Natl Cancer Inst 2011; 103:763-73.

3. Rini BI, Schiller JH, Fruehauf JP, et al. Diastolic blood pressure as a biomarker of axitinib efficacy in solid tumors. Clin Cancer Res 2011; 17:3841-9.

4. Li Y, Li S, Zhu Y, et al. Incidence and risk of sorafenib-induced hypertension: a systematic review and meta-analysis. J Clin Hypertens (Greenwich) 2014; 16:177-85.

5. Bono P, Rautiola J, Utriainen T, Joensuu H. Hypertension as predictor of sunitinib treatment outcome in metastatic renal cell carcinoma. Acta Oncol 2011; 50:569-73.

6. Wei W, Jin H, Chen ZW, Zioncheck TF, Yim AP, He GW. Vascular endothelial growth factor-induced nitric oxide- and PGI2-dependent relaxation in human internal mammary arteries: a comparative study with KDR and Flt-1 selective mutants. J Cardiovasc Pharmacol 2004; 44:615-21.

7. Yang R, Thomas GR, Bunting S, et al. Effects of vascular endothelial growth factor on hemodynamics and cardiac performance. J Cardiovasc Pharmacol 1996; 27:838-44.

8. Steeghs N, Gelderblom H, Roodt JO, et al. Hypertension and rarefaction during treatment with telatinib, a small molecule angiogenesis inhibitor. Clin Cancer Res 2008; 14:3470-6.

9. Dechend R, Luft FC. Angiogenesis factors and preeclampsia. Nat Med 2008; 14 1187-8.

10. Chow WH, Dong LM, Devesa SS. Epidemiology and risk factors for kidney cancer. Nat Rev Urol 2010; 7:245-57.

11. Haggstrom C, Rapp K, Stocks T, et al. Metabolic factors associated with risk of renal cell carcinoma. PLoS One 2013; 8:e57475.

12. Izzedine H, Derosa L, Le Teuff G, Albiges L, Escudier B. Hypertension and angiotensin system inhibitors: impact on outcome in sunitinib-treated patients for metastatic renal cell carcinoma. Ann Oncol 2015; 26:1128-33.

13. Egami K, Murohara T, Shimada T, et al. Role of host angiotensin II type 1 receptor in tumor angiogenesis and growth. I Clin Invest 2003; 112:67-75.

14. Noguchi R, Yoshiji H, Ikenaka Y, et al. Synergistic inhibitory effect of gemcitabine and angiotensin type-1 receptor blocker, losartan, on murine pancreatic tumor growth via anti-angiogenic activities. Oncol Rep 2009; 22:355-60.

15. Noguchi R, Yoshiji H, Kuriyama S, et al. Combination of interferon-beta and the angiotensin-converting enzyme inhibitor, perindopril, attenuates murine hepatocellular carcinoma development and angiogenesis. Clin Cancer Res 2003; 9: 6038-45. 


\section{Angiotensin Inhibitors and mRCC}

16. Yoshiji H, Kuriyama S, Noguchi R, Fukui H. Angiotensin-I converting enzyme inhibitors as potential anti-angiogenic agents for cancer therapy. Curr Cancer Drug Targets 2004; 4:555-67.

17. Dolley-Hitze T, Jouan F, Martin B, et al. Angiotensin-2 receptors (AT1-R and AT2-R), new prognostic factors for renal clear-cell carcinoma? Br J Cancer 2010; 103:1698-705.

18. Keizman D, Huang P, Eisenberger MA, et al. Angiotensin system inhibitors and outcome of sunitinib treatment in patients with metastatic renal cell carcinoma: a retrospective examination. Eur I Cancer 2011; 47:1955-61.

19. McKay RR, Rodriguez GE, Lin X, et al. Angiotensin system inhibitors and surviva outcomes in patients with metastatic renal cell carcinoma. Clin Cancer Res 2015; 21:2471-9.

20. Therasse P, Arbuck SG, Eisenhauer EA, et al. New guidelines to evaluate the response to treatment in solid tumors. European Organization for Research and Treatment of Cancer, National Cancer Institute of the United States, Nationa Cancer Institute of Canada. I Natl Cancer Inst 2000; 92:205-16.

21. Trotti A, Colevas A, Setser A, et al. CTCAE v3.0: development of a comprehensive grading system for the adverse effects of cancer treatment. Semin Radiat Oncol 2003; 13:176-81.
22. Heng DYC, Xie W, Regan MM, et al. Prognostic factors for overall survival in patients with metastatic renal cell carcinoma treated with vascular endothelial growth factor-targeted agents: results from a large, multicenter study. JClin Oncol 2009; 27:5794-9.

23. Deshayes F, Nahmias C. Angiotensin receptors: a new role in cancer? Trends Endocrinol Metabol 2005; 16:293-9.

24. Rosenthal T, Gavras I. Angiotensin inhibition and malignancies: a review. J Hum Hypertens 2009; 23:623-35.

25. Miyajima A, Kosaka T, Asano T, et al. Angiotensin II type I antagonist prevents pulmonary metastasis of murine renal cancer by inhibiting tumor angiogenesis. Cancer Res 2002; 62:4176-9.

26. Verhoest G, Dolley-Hitze T, Jouan F, et al. Sunitinib combined with angiotensin2 type-1 receptor antagonists induces more necrosis: a murine xenograft model of renal cell carcinoma. Biomed Res Int 2014; 2014:901371.

27. Arafat HA, Gong Q, Chipitsyna G, Rizvi A, Saa CT, Yeo CJ. Antihypertensives as novel antineoplastics: angiotensin-I-converting enzyme inhibitors and angiotensin II type 1 receptor blockers in pancreatic ductal adenocarcinoma. I Am Coll Surg 2007; 204:996-1005, discussion: 1005-6.

28. Yoshiji H, Noguchi R, Ikenaka Y, Kaji K, Aihara Y, Fukui H. Impact of renin-angiotensin system in hepatocellular carcinoma. Curr Cancer Drug Targets 2011; 11:431-41. 
Supplemental Table 1 Patient Characteristics by HTN and ASI User Status at Baseline

\begin{tabular}{|c|c|c|c|c|c|c|c|}
\hline & \multicolumn{3}{|c|}{ HTN at Baseline } & \multicolumn{3}{|c|}{ ASI as anti-HTN Medication at Baseline } & \multirow[b]{2}{*}{$\begin{array}{l}\text { Total } \\
\text { N (\%) }\end{array}$} \\
\hline & $\begin{array}{c}\text { Yes } \\
\text { N (\%) }\end{array}$ & $\begin{array}{c}\text { No } \\
\text { N (\%) }\end{array}$ & $\boldsymbol{P}$ & $\begin{array}{c}\text { Yes } \\
\text { N (\%) }\end{array}$ & $\begin{array}{c}\text { No } \\
\text { N (\%) }\end{array}$ & $\boldsymbol{P}$ & \\
\hline Total & 197 & 106 & & 126 & 177 & & 303 \\
\hline \multicolumn{8}{|l|}{ Gender } \\
\hline Male & $127(64.5)$ & $66(62.3)$ & .71 & $83(65.9)$ & $110(62.1)$ & .55 & $193(63.7)$ \\
\hline Female & $70(35.5)$ & $40(37.7)$ & & $43(34.1)$ & $67(37.9)$ & & $110(36.3)$ \\
\hline \multicolumn{8}{|l|}{$\mathrm{Age}^{\mathrm{a}}$} \\
\hline Median & 67 & 64 & .015 & 67 & 66 & .04 & 67 \\
\hline Range & $39-92$ & $22-82$ & & $39-89$ & $22-92$ & & $22-92$ \\
\hline \multicolumn{8}{|l|}{ WHO } \\
\hline $0-1$ & $161(81.7)$ & $83(78.3)$ & .54 & $104(82.5)$ & $140(79.1)$ & .56 & $244(80.5)$ \\
\hline$>1$ & 36 (18.3) & $23(21.7)$ & & 22 (17.5) & 37 (20.9) & & 59 (19.5) \\
\hline \multicolumn{8}{|l|}{ Prior nephrectomy } \\
\hline Yes & 159 (80.7) & $82(77.4)$ & .55 & 105 (83.3) & 136 (76.8) & .19 & 241 (79.5) \\
\hline No & 38 (19.3) & $24(22.6)$ & & 21 (16.7) & 41 (23.2) & & $62(20.5)$ \\
\hline \multicolumn{8}{|l|}{ Histology } \\
\hline Clear-cell & 142 (89.3) & 70 (83.3) & .23 & 94 (91.3) & 118 (84.3) & .12 & $212(87.2)$ \\
\hline Non-clear-cell & 17 (10.7) & $14(16.7)$ & & $9(8.7)$ & $22(15.7)$ & & 31 (12.8) \\
\hline Missing & 38 & 22 & & 23 & 37 & & 60 \\
\hline \multicolumn{8}{|l|}{$\begin{array}{l}\text { No. of metastatic } \\
\text { sites }\end{array}$} \\
\hline $0-1$ & 56 (28.4) & $28(26.4)$ & .79 & 32 (25.4) & $52(29.4)$ & .52 & $84(27.7)$ \\
\hline$>1$ & 141 (71.6) & 78 (73.6) & & 94 (74.6) & 125 (70.6) & & 219 (72.3) \\
\hline \multicolumn{8}{|l|}{ Heng criteria } \\
\hline Favorable & 30 (16.2) & $19(18.3)$ & .52 & $25(21.0)$ & 24 (14.1) & .21 & $49(17.0)$ \\
\hline Intermediate & 97 (52.4) & $42(40.4)$ & .05 & 59 (49.6) & $80(47.0)$ & .72 & $139(48.1)$ \\
\hline Poor & 58 (31.4) & $43(41.3)$ & .13 & 35 (29.4) & 66 (38.8) & .13 & 101 (34.9) \\
\hline Missing & 12 & 2 & & 7 & 7 & & 14 \\
\hline \multicolumn{8}{|l|}{ Treatment } \\
\hline Sunitinib & 171 (86.8) & $96(90.6)$ & .36 & 106 (84.1) & 161 (91.0) & .075 & 267 (88.1) \\
\hline Pazopanib & $26(13.2)$ & $10(9.4)$ & & $20(15.9)$ & $16(9.0)$ & & $36(11.9)$ \\
\hline
\end{tabular}

Abbreviations: $\mathrm{ASI}=$ angiotensin system inhibitors: HTN = hypertension; WHO $=$ World Health Organization.

aPatients with HTN and with ASI were significantly older compared with patients without HTN and ASI, respectively. Other patient characteristics were not associated with either HTN status or ASI user status. 
Angiotensin Inhibitors and mRCC

\section{Supplemental Table 2 Potential Prognostic Factors for OS and PFS in Patients With mRCC}

\begin{tabular}{|c|c|c|c|c|c|c|c|}
\hline & \multirow[b]{2}{*}{$\mathbf{N}$} & \multicolumn{3}{|c|}{ OS (mos) } & \multicolumn{3}{|c|}{ PFS (mos) } \\
\hline & & $\begin{array}{l}\text { Median } \\
(95 \% \text { CI) }\end{array}$ & $\begin{array}{c}\text { HR } \\
(95 \% \text { Cl) }\end{array}$ & $P$ & $\begin{array}{l}\text { Median } \\
(95 \% \text { Cl) }\end{array}$ & $\begin{array}{c}\text { HR } \\
(95 \% \text { Cl) }\end{array}$ & $P$ \\
\hline \multicolumn{8}{|l|}{ Age, y } \\
\hline $20-59$ & 72 & $21.3(12.6-29.9)$ & 1.00 & & $7.2(5.8-8.6)$ & 1.00 & \\
\hline $60-69$ & 115 & $19.5(14.0-25.0)$ & $1.06(0.74-1.51)$ & .75 & $7.3(5.2-9.4)$ & $0.92(0.67-1.27)$ & .62 \\
\hline $70-92$ & 116 & $20.9(16.2-25.6)$ & $1.12(0.79-1.60)$ & .52 & $10.1(7.1-13.2)$ & $0.83(0.60-1.14)$ & .83 \\
\hline \multicolumn{8}{|l|}{ Heng criteria } \\
\hline Favorable & 49 & $42.4(35.5-49.3)$ & 1.00 & & $24.6(13.4-35.7)$ & 1.00 & \\
\hline Intermediate & 139 & $22.6(18.3-26.9)$ & $1.81(1.19-2.77)$ & .006 & $8.5(6.2-10.9)$ & $2.00(1.37-2.39)$ & $<.001$ \\
\hline Poor & 101 & $8.1(6.2-10.0)$ & $4.70(3.02-7.31)$ & $<.001$ & $5.1(4.1-6.1)$ & 4.08 (2.73-6.12) & $<.001$ \\
\hline \multicolumn{8}{|l|}{ Prior nephrectomy } \\
\hline No & 62 & $8.2(6.2-10.0)$ & 1.00 & & $5.3(3.9-6.7)$ & 1.00 & \\
\hline Yes & 241 & $23.4(18.2-28.7)$ & $0.36(0.27-0.50)$ & $<.001$ & $9.4(6.7-12.1)$ & $0.47(0.35-0.63)$ & $<.001$ \\
\hline \multicolumn{8}{|c|}{ No. of metastatic sites } \\
\hline 1 & 84 & $29.5(21.5-37.5)$ & 1.00 & & $13.7(9.5-17.9)$ & 1.00 & \\
\hline$>1$ & 219 & $15.7(11.5-20.0)$ & $1.58(1.16-2.16)$ & .004 & $6.7(5.8-7.6)$ & $1.52(1.14-2.02)$ & .004 \\
\hline \multicolumn{8}{|l|}{ Histology } \\
\hline Non-clear-cell & 31 & $13.9(5.9-21.9)$ & 1.00 & & $5.8(3.5-8.1)$ & 1.00 & \\
\hline Clear-cell & 212 & $23.1(17.1-29.1)$ & $0.65(0.43-1.00)$ & .05 & $9.4(6.5-12.3)$ & $0.61(0.40-0.91)$ & .02 \\
\hline \multicolumn{8}{|l|}{ HTN at baseline } \\
\hline No & 106 & $20.1(15.5-24.7)$ & 1.00 & & $8.2(5.4-11.0)$ & 1.00 & \\
\hline Yes & 197 & $20.3(16.4-24.2)$ & $1.09(0.82-1.45)$ & .54 & $8.2(6.6-9.7)$ & $1.05(0.81-1.36)$ & .72 \\
\hline \multicolumn{8}{|c|}{$\begin{array}{l}\text { Use of anti-HTN } \\
\text { medication at baseline }\end{array}$} \\
\hline $\begin{array}{l}\text { No anti-HTN } \\
\text { medication }\end{array}$ & 106 & $20.1(15.5-24.7)$ & 1.00 & & $8.2(5.4-11.0)$ & 1.00 & \\
\hline ASI & 126 & $22.3(18.9-25.7)$ & $1.00(0.74-1.38)$ & .96 & $8.6(6.3-10.9)$ & $1.00(0.75-1.32)$ & .98 \\
\hline $\begin{array}{l}\text { Other anti-HTN } \\
\text { medication }\end{array}$ & 71 & $16.5(10.8-22.2)$ & $1.26(0.89-1.79)$ & .20 & $7.3(5.0-9.6)$ & $1.15(0.83-1.59)$ & .41 \\
\hline \multicolumn{8}{|c|}{ Treatment-induced HTN } \\
\hline No & 193 & $13.9(10.4-17.4)$ & 1.00 & & $6.4(5.6-7.3)$ & 1.00 & \\
\hline Yes & 110 & $34.9(28.2-41.6)$ & $0.41(0.30-0.55)$ & $<.001$ & $15.6(11.6-19.7)$ & $0.43(0.33-0.56)$ & $<.001$ \\
\hline \multicolumn{8}{|l|}{$\begin{array}{l}\text { ASI use as } \\
\text { treatment-related } \\
\text { anti-HTN medication }\end{array}$} \\
\hline No & 232 & $16.5(12.9-20.2)$ & 1.00 & & $6.6(5.8-7.5)$ & 1.00 & \\
\hline Yes & 71 & $37.7(26.0-49.5)$ & $0.38(0.26-0.54)$ & $<.001$ & 16.7 (6.1-27.2) & $0.41(0.30-0.57)$ & $<.001$ \\
\hline
\end{tabular}

Abbreviations: $\mathrm{ASI}=$ angiotensin system inhibitors; $\mathrm{Cl}=$ confidence interval; $\mathrm{HR}=$ hazard ratio; $\mathrm{HTN}=$ hypertension; $\mathrm{mRCC}=$ metastatic renal cell carcinoma; $0 \mathrm{~S}=$ overall survival; PFS = progression-free survival. 


\begin{tabular}{|c|c|c|c|c|}
\hline \multirow[t]{3}{*}{ Supplemental Table 3} & \multicolumn{4}{|c|}{$\begin{array}{l}\text { Patient Characteristics Among Patients With TKI-induced HTN for ASI Users }(n=91) \text { and ASI Nonusers } \\
(n=19)\end{array}$} \\
\hline & \multicolumn{2}{|c|}{ ASI User Status } & \multirow[b]{2}{*}{$\boldsymbol{P}$} & \multirow[b]{2}{*}{$\begin{array}{l}\text { Total } \\
\text { N (\%) }\end{array}$} \\
\hline & $\begin{array}{l}\text { Yes } \\
\text { N (\%) }\end{array}$ & $\begin{array}{l}\text { No } \\
\text { N (\%) }\end{array}$ & & \\
\hline Total & 91 & 19 & & 110 \\
\hline \multicolumn{5}{|l|}{ Gender } \\
\hline Male & $58(63.7)$ & $9(47.4)$ & .20 & $67(60.9)$ \\
\hline Female & $33(36.3)$ & $10(52.6)$ & & $43(39.1)$ \\
\hline \multicolumn{5}{|l|}{ Age, y } \\
\hline Median & 65 & 66 & .56 & 65 \\
\hline Range & $22-89$ & $43-78$ & & $22-89$ \\
\hline \multicolumn{5}{|l|}{ WHO } \\
\hline $0-1$ & $84(92.3)$ & $18(94.7)$ & 1.00 & $102(92.7)$ \\
\hline$>1$ & $7(7.7)$ & $1(5.3)$ & & $8(7.3)$ \\
\hline \multicolumn{5}{|l|}{ Prior nephrectomy } \\
\hline Yes & $83(91.2)$ & $15(78.9)$ & .22 & $98(89.1)$ \\
\hline No & $8(8.8)$ & $4(21.1)$ & & $12(10.9)$ \\
\hline \multicolumn{5}{|l|}{ Histology } \\
\hline Clear-cell & $71(84.5)$ & $13(86.7)$ & 1.00 & $84(84.8)$ \\
\hline Non-clear-cell & $13(15.5)$ & $2(13.3)$ & & $15(15.2)$ \\
\hline Missing & 7 & 4 & & 11 \\
\hline \multicolumn{5}{|l|}{ No. of metastatic sites } \\
\hline $0-1$ & $30(33.0)$ & $6(31.6)$ & 1.00 & $36(32.7)$ \\
\hline$>1$ & $61(67.0)$ & $13(68.4)$ & & $74(67.3)$ \\
\hline \multicolumn{5}{|l|}{ Heng criteria } \\
\hline Favorable & $25(29.1)$ & $4(23.5)$ & .78 & 29 (28.2) \\
\hline Intermediate & $46(53.5)$ & $9(52.9)$ & 1.00 & $55(53.4)$ \\
\hline Poor & $15(17.4)$ & $4(23.5)$ & .51 & 19 (18.4) \\
\hline Missing & 5 & 2 & & 7 \\
\hline \multicolumn{5}{|l|}{ Treatment } \\
\hline Sunitinib & 73 (86.8) & $16(90.6)$ & 1.00 & 89 (80.9) \\
\hline Pazopanib & 18 (13.2) & $3(9.4)$ & & 21 (19.1) \\
\hline
\end{tabular}

Abbreviations: ASI = angiotensin system inhibitors; HTN = hypertension; TKI = tyrosine kinase inhibitors; WHO = World Health Organization. 